\title{
PRIVATISATION OF HOSPITALS IN POLAND - BARRIERS AND OPPORTUNITIES
}

\author{
Krzysztof Krajewski-Siuda, Piotr Romaniuk \\ Department of Health Policy, Faculty of Public Health, Medical University of Silesia, Bytom, Poland
}

\begin{abstract}
SUMMARY
The paper discusses the question of privatisation of the in-patient care sector in Poland. The references to the general reforming processes are made, as well as the legal context of ownership changes is presented. First part of the article describes the forms of privatisation applied in Poland, such as privatisation of the management, partial privatisation, functional privatisation and total privatisation. The basic data concerning legal regulations currently being in force is also included. Legal status is an important obstacle for the process of privatisation, since the regulations are incoherent and ambiguous. The project of Commercialisation and Privatisation of Independent Public Health Care Facilities Law was presented in 2001, but the political situation was unfavourable for such a regulation. The paper discusses also the potential profits that may be gathered during the privatisation, which may be proved by the experiences in the field of out-patient care, as well as the examples of other countries. It is stated that success of privatisation depends on changes in the structure of sources of financing health care system. The last part of the article describes the previous course of privatisation processes of in-patient sector. Presently about $18 \%$ of hospitals in Poland are private facilities, but their role in the system is marginal. The case of hospital in Więcbork, which was the first bankrupt private hospital in Poland, is presented as the example of dangers caused by the invalid law. The final conclusion is that there is an urgent need in Poland to create clear and coherent legal frames for the privatisation of hospitals, as well as harmonisation of the changes with general reforms of the health care system.
\end{abstract}

Key words: privatisation, restructurisation, hospitals, in-patient care, Poland

Address for correspondence: K. Krajewski-Siuda, Department of Health Policy, Faculty of Public Health, Medical University of Silesia, ul. Piekarska 18, 41 - 902 Bytom, Poland. E-mail: zpz@slam.katowice.pl

\section{INTRODUCTION}

The question of privatisation in the health care sector, particularly hospitals, is one of the most intensively discussed matters referring to the area of public health in Poland. In recent weeks the problem has been introduced to the public discourse again, when the government's project of law concerning public support and restructurisation of the public health care facilities was proclaimed $^{1}$. Proponents of the massive privatisation of the hospitals are hoping that this process will significantly improve the quality of health services, as well as positively influence the efficacy of the Polish health care system. On the contrary, the opponents criticise privatisation as a menace to the interests of the professional groups in health care system. The second option is presented mainly by the followers of the public health care model and representatives of the lower health care personnel (i.e. trade unions and nurses' self-government). In fact, such a situation in Poland is not an unusual case. The privatisation was equally controversial also in other Central East Europen countries being under transformation, such as Slovakia and Hungary, where last year a nationwide referendum in this matter was held (1). Nevertheless, it is true, that Poland is a step behind its neighbours, both in the general health care transformation processes, and privatisation in particular. For example, in the Czech Republic about $21 \%$ of hospitals are the private units $(2,3)$, with reservation that these are mainly small units with very limited number of beds (4). Also in Lithuania, after a long period of stagnation, recently the government decided to bring in the new regulations aimed at significant simplification of the privatisation processes (5).

The aim of this article is to make a short recap of the discussion concerning privatisation of hospitals which is held in Poland, as well as to sum up Polish experiences in this area in recent years.

\section{THE FORMS OF PRIVATISATION OF HEALTH CARE UNITS IN POLAND}

Privatisation is defined as the "process of transferring ownership rights concerning the defined kind of resources from a public entity to private bodies, with a simultaneous liquidation of the organisational unit which previously was using these resources" (6). A few different forms of privatisation in the health care system can be separated, based on Polish literature. First is the privatisation of management, which may be understood as a change of the rules concerning the hospital management. In that case, the director is not employed by the hospital as a full-time worker, but he is bounded to the facility with the civil law agreement, and is acting as a one-person managing company. Proponents of this form are raising the arguments that it is profitable for both sides: the manager and the hospital. Director has the guarantee of wide independence from the hospitals' founding body, while the other side may more effectively control the efficacy of management (7). This form occurs in Polish health care system; however it is difficult to estimate its scale. The example of its successful appli-

\footnotetext{
${ }^{1}$ Sejm - the lower chamber of Polish Parliament - has rejected the project, but it was reintroduced as a presidential initiative.
} 
cation may be the Ministry's of Home Affairs and Administration Hospital in Krakow (8).

Second form is the partial privatisation (7), which may be also described as the outsourcing of ancillary services. In this case, the public health care facilities signs contracts with private corporations specialised in cleaning, catering, etc. The basic profits for the unit which decides to implement this form of privatisation are the financial savings and shifting the responsibility for employing and maintenance of non-medical personnel to the private contractor. This form is commonly applied in Polish hospitals.

When referring to the performance of the health care system, the most important are two another forms of privatisation, which are the most advanced of all that are mentioned in this article. These forms are the privatisation of services, and the total privatisation. First form means that the health services provision is contracted with private entities. Nevertheless, these entities are acting on the basis of public infrastructure, which is given to them for rent (7). This form is also being called the functional privatisation (9). The second form consists in the total transfer of the ownership over the infrastructure being a base for health services provision from public owner to the private body (7). Due to the fact, that it requires the engagement of major financial funds, it is claimed that this form is the most difficult to be applied in practice in the in-patient care sector. Nonetheless, it shall be stated that it is possible to apply this form in Polish health care system, as the investments in hospitals is a point of interest of international medical corporations (10).

Both of the most advanced forms of privatisation have been widely applied on the ground of primary and secondary out-patient care $^{2}$ after the decentralisation reform in 1999, which is confirmed by the dynamic increase of the number of contracts with private providers into which the public payer has entered since the reform. The detailed data are presented in Table 1 .

As the Table shows, the number of admissions in public primary health care facilities decreased by $40 \%$ after 2 years from the beginning of the reform. At the same time number of admissions in non-public facilities increased by nearly $250 \%$. General number of admissions provided by private primary health care facilities was in 2001 of about 10 millions higher than the number of admissions provided by public facilities. In the secondary outpatient care the public sector was still dominating in 2001, but the number of admissions provided by private facilities increased from 1999 by nearly $500 \%$.

Table 1. Admissions in public and non-public out-patient health care facilities (millions)

\begin{tabular}{|l|c|c|c|c|c|c|}
\hline & \multicolumn{3}{|c|}{$\begin{array}{c}\text { Primary } \\
\text { health care }\end{array}$} & \multicolumn{4}{c|}{$\begin{array}{c}\text { Secondary } \\
\text { care }\end{array}$} \\
\cline { 2 - 7 } & $\mathbf{1 9 9 9}$ & $\mathbf{2 0 0 0}$ & $\mathbf{2 0 0 1}$ & $\mathbf{1 9 9 9}$ & $\mathbf{2 0 0 0}$ & $\mathbf{2 0 0 1}$ \\
\hline Public facilities & 105,6 & 78,4 & 61,7 & 54,1 & 50,9 & 49,3 \\
\hline $\begin{array}{l}\text { Non public facilities } \\
\text { and practices }\end{array}$ & 20,6 & 48,3 & 72 & 4 & 10,3 & 23,9 \\
\hline
\end{tabular}

Source: Włodarczyk C. Health reforms. Uniwersalny kłopot. Kraków: Wydawnictwo Uniwersytetu Jagiellońskiego; 2003 (in Polish) (11).
The data presented above may be a good evidence for the thesis, that privatisation of the out-patient care caused positive results both for the effectiveness of the health care system and the quality of services. It is also confirmed by the opinions of patients, who noticed the improvement of the quality of services, as well as the difference in this area between public and non-public providers, of which the second group received significantly better notes (11).

Having regard to the described facts, it seems that the profits of the privatisation of health care sector are evident. There are no logical premises for the thesis that in case of the in-patient care the positive results of privatisation will not appear in equal extent. It is therefore difficult to explain the reasons of intensive objection against the change of ownership structure within hospital sector. It may become understandable only partially after the analysis of rhetoric used by opponents of the privatisation. Most frequently the opposition is using three kinds of arguments:

- Privatisation causes the need of patients' direct payments for services.

- Privatisation, particularly uncontrolled (in Poland such a process is called the "wild privatisation"), and introduction of market rules into the hospital sector may cause the bankruptcy of some facilities unable to act on the market of health services. In result the equity of access to services may be broken, or the general accessibility to services may be limited.

- Privatisation is tightly connected with the reduction of employment, which may cause the increase of unemployment rate among medical professionals.

First of the presented arguments is probably the most important reason of the public opinion's unwillingness to the privatisation of in-patient care. However, it arises of an evident misunderstanding caused by the habits typical for the Soviet Semashko model, where the private providers had no place within the health care system financed from the public resources. In fact, there are no formal or practical obstacles in Poland for the model in which the public payer signs contracts with non-public providers, just as it is already functioning in the out-patient care. The second argument seems to have some rational basis. Nevertheless, there are many examples of countries, which have decided to open the in-patient care sector for private ownership and the accessibility and equity did not decrease. One of the examples of the successful combination of the public financing and private provision of the services is Holland (11). Third argument derives of evident and partly understandable fears of health care workers, for whom the basic interest is to maintain the employment and social safety. Nevertheless, it should be underlined that this aim is in contradiction with the general purpose of increasing the organisational and financial efficacy of health care system. In that context, the reduction of employment would probably be a phenomenon with positive effect. On the other hand, the actual reduction of employment would probably be lower than the number of health care workers dismissed from the restructurised hospitals. A part of the free workforce would be absorbed by the new developing sectors, just as the long-term and palliative care. It should also

\footnotetext{
2 Primary health care in Poland is referred mainly to the services of general practitioners and family doctors (the assumed terminal form of primary health care), as well as paediatricians. It refers also to the dental care, which however is contracted and financed based on separate rules. Dental care is provided mainly by private facilities and practices.
} 
not be omitted that after accession of Poland to European Union and work migrations of numerous physicians and other health care workers to "old" EU member states, there is rather a danger of scarcity of highly qualified medical professionals, not the excess of free medical workforce. It may be expected that in case of wider restructurisation of the in-patient care sector, part of the free workforce would be absorbed also by the work markets in other EU Member States. Finally, it should be underlined the lack of guarantee of permanent employment and the exaction of higher efficiency of the privatised facilities' workers should be compensated by the significant increase of incomes.

\section{PRIVATISATION IN THE CONTEXT OF HEALTH CARE SYSTEM REFORM IN POLAND}

In 1999 the health care system in Poland has been substantially reformed. The main assumptions of the reform were to replace the communist Semashko model and the central public financing with the system of health insurance funds. The sixteen regional health funds (called "sickness funds") were established (one fund in each voivodeship - the biggest administrative unit in Poland ${ }^{3}$ ) and one professional fund for so-called "uniformed services" (soldiers, policemen etc.) (12). The reform assumed also significant changes in the structure of health care providers. "Money follows the patient" was declared as a basic rule of new system, which in practice meant that health the care facilities should compete with each other, while patients are allowed to decide which provider to choose. All public health care entities were obligatory transformed into "independent health care facilities", which was tantamount to deep decentralisation (delegation) of the management. Afterwards, the system financed from the public resources was also opened for the activity of the private providers. The main bodies holding ownership over the public facilities became the local self-government administration units. The units had the right to decide at the discretion about privatisation of their facilities, which referred also to the hospitals. Having regarded to the fact that decentralisation of health care system was another substantial assumption of the reform project; this construction shall be seen as a consistent course of transformation. Systematically the consecutive stages of decentralisation were applied: devolution, delegation and privatisation $(13,14)$. However it is important to emphasize that the described assumptions of the reform were not fully realised in practice. The National Health Insurance Act contained a paragraph providing a regulation that after two years from the establishing of the health insurance also the private funds should enter the system and freely compete with the public sickness funds. This regulation was then delayed and did not come into force, while in fact this was an essential condition for the realisation of the rule "money follows the patient". Without the competition among the health funds, a monopsony of regional sickness funds existed, and the funds were dominating over providers and could dictate the provisos of contracts. In this situation the money flows within the system were determined by the decisions of regional sickness funds, not the patients (11). The only one step taken in Poland towards the competition among the funds was the introduction of the patient's right to choose the sickness fund at the discretion. However, the system was dominated by regional funds, which caused the competition was only an appearance. Only the sole professional fund which functioned on the whole territory of Poland could compete with regional sickness funds, but its position was too weak (15).

The described above situation of payer's monopsony may be a serious obstacle for the development of non-public providers, particularly if the institution of payer is strongly dependent on the political determinants. It is possible that the health insurance institution, being obliged to accomplish a concrete political vision, will significantly limit the number of contracts with private health care providers. In result, private facilities, having no access to the basic source of financing health services, would be pushed into the niche of luxury services financed wholly from the private resources of patients. Many of such elements could be frequently observed after replacing the system of sickness funds with central health insurance institution - the National Health Fund established in 2003. Centralisation of the system additionally caused a danger that the contracting policy preferring public providers will be applied to the whole country, not only an individual region.

\section{THE LEGAL FORMS OF PRIVATISATION IN POLAND}

There is a substantial lack of the clear legal regulations concerning privatisation of hospitals in Poland. The regulations currently being in force are contained in the Health Care Facilities Act. The law provides three ways of privatisation: division, transformation (applied in case of partial privatisation) and liquidation (applied in case of total privatisation) of the independent public health care facility. The decision concerning which form should be applied in particular case is taken by the body holding ownership over the facility, which is most frequently the local self-government unit. The law forbids public owners to establish a non-public health care facility. It is also uncertain if the commercial company established by public body has such a possibility (16). If public owner decides to liquidate the facility, it is obliged to define how patients, for whom the facility was serving, will be ensured access to the health care. In other words, liquidation cannot cause the limitation of the access to services. If analogous non-public providers exist in the nearest area, this condition is met, however it is suggested that such providers should exist before the public facility is liquidated. Besides, the decision concerning liquidation shall be consulted with all potentially concerned institutions, such as the government's regional representative (wojewoda), the municipality or poviat councils or the regional assembly (sejmik wojewódzki). Nevertheless, opinions of such bodies are not binding. Public owner dispose with the property and infrastructure of liquidated facility. If the owner decides to transfer the property to a private entity providing health services, it is tantamount to the privatisation (total) of the previous public facility (16).

\footnotetext{
3 In 1999 the major project of four social spheres reform was introduced in Poland: education, social insurance, health care system and public administration. In the fourth area the reform assumed deep decentralisation of public authorities, which resulted in establishing three levels of self-government: gmina (parish, municipality - the basic level), powiat (poviat, county - the middle level) and województwo (voivodeship, region - the regional level). On the regional level, besides of self-government administration (legislative assembly - sejmik wojewódzki, and executive body - marszałek), remained the direct representative of the central governmental administration (wojewoda). This was aimed at ensuring the realisation of governmental policy goals at the regional level.
} 
Functional privatisation (privatisation of services) is a process legally even more complicated. This form occurs when the public facility still exists (or is being transformed), but its property and its workers are leased to the non-public provider. Formally the public facility sings contract with private provider and is buying from this provider the health services that were previously produced by this public facility itself. This process is called in Poland the "subcontracting". Although, it is also possible that private provider signs contract directly with the payer, while the public facility formally ends to provide health services. It can be therefore stated, that functional privatisation is equal to the extension of what was earlier called the "partial privatisation" to the medical procedures. However, there are difficulties with interpretation of this legal construction in the context of Medical Profession Act, which states that the "group medical practice cannot be performed in public health care facility, based on the civil law contract on provision of health services" (16).

The presented short description of legal possibilities concerning privatisation of in-patient sector in Poland confirms that the regulations are not unambiguous, which causes that frequently actions taken in this area are legally uncertain. Such a situation is a ground susceptible to abuses, which publicised in media increases the public opinion's aversion to the privatisation in general. The strong need of enforcing the clear regulations is therefore evident. An effort in this matter was taken yet in 2001, shortly before the general elections, when the Ministry of Health prepared and presented to the Parliament the project of Law on Commercialisation and Privatisation of Independent Public Health Care Facilities. However, due to the strongly unfavourable political conditions (forthcoming elections, breakdown of the governing coalition and a strong political disintegration), the project has not even been voted in Sejm (lower chamber of Parliament). This act is a good example showing the course of discussion concerning in-patient care privatisation in Poland. As the analysis of the chances of its implementation proved, apart from the general political situation, the matter of privatisation itself generated an opposition unwilling to accept any changes of ownership structure (17). Analogically, when the previous government proposed a legal act concerning restructurisation and public support for the public health care facilities, the large part of political class, as well as the medical professional environment, declared an intensive objection against it, although in fact the project did not assumed privatisation ${ }^{4}$ in the strict meaning of this term.

\section{PREVIOUS COURSE OF PRIVATISATION PRO- CESSES IN POLAND}

The term "privatisation" used in this section will refer to the two most advanced forms described above.

The first non-public hospital in post-communist Poland was the Bonifrater Order's Hospital in Krakow. The hospital was nationalised in 1949, and then returned to the Order in 1997 (18). In
2004, due to the data of the Ministry of Health, the total number of non-public hospitals in Poland ${ }^{5}$ was 147 , in comparison with 643 public facilities (19). This means that $18.6 \%$ of in-patient facilities in Poland are the private units, which may seem a significant number. However, the number of beds in private hospitals equalled at the same time to only $4.2 \%$ of the total number of hospital beds in Poland $(183,280$, which amounts to 480 beds per 100,000 population) (19). Besides, the effectiveness of use in private hospital was lower than in public facilities: bed occupancy amounted to $62 \%$ in 2004 , in comparison with $72.2 \%$ in public hospitals. On the contrary, the average length of stay in public hospitals was higher (6.9 days vs 5.8 days in private hospitals). Similarly, the number of admitted patients in reference to one bed is also higher in the non-public facilities (38.7 vs 38.2 in public hospitals) (19). This probably results in the higher costs and the lower general economic effectiveness in the public units.

Despite of the generally significant number of private hospitals, the role of private sector in in-patient care in Poland is still marginal. According to the data of the Polish Private Hospitals Association, its members signed in 2005 contracts with the National Health Fund for total amount of $0.44 \%$ of all resources assigned for health services (20). Even with reservation that not all private hospitals are members of the Association [currently it has 62 members (21)] such a thesis will be justifiable. It may be additionally confirmed also by the data concerning general allocation of public resources in Poland to private and public health care providers. Despite of dynamically increasing - as shown above - number of admissions in private ambulatory facilities, the role of public sector is still predominant. While the estimated total resources of health care system in Poland in 2003 were PLN 53.6 milliards (EUR 13.7 milliards; excluding informal payments), the share of costs of private providers (including the costs of pharmaceutics used by the providers) in this amount was 19.7\% (PLN 10.5 milliards; EUR 2.7 milliards), in comparison with $40.1 \%$ (PLN 21.5 milliards; EUR 5.5 milliards; including pharmaceutics) share for public facilities ${ }^{6}$. Only $56.5 \%$ (PLN 5.9 milliards; EUR 1.5 milliards) of the costs of private providers was covered from public resources; the rest are the services fully covered by the out-of-pocket payments (22). In 2003 only slightly above $20 \%$ of all contracts was signed by the public payer with the private providers (22).

There are at least few possible reasons of this situation. First may be the described monopsony of payer, particularly after replacing the regional sickness funds with the National Health Fund. Although, the monopsony of one central insurance institution itself do not determine a barrier for the process of privatisation, in fact the contracts presented by the newly established National Health Funds were significantly limiting access of private hospitals to public health insurance resources (23).

The negative impact on the process of privatisation of the inpatient care caused by the political determinants and the invalid legal regulations is well seen in the case of Poviat's Hospital in Więcbork. By the decision of poviat authorities in Sępólno Kra-

\footnotetext{
${ }^{4}$ The main reason of objection was a provision assuming that public hospitals will act on the basis of commercial law, which provides the possibility of bankruptcy.

${ }^{5}$ Not all of private hospitals were established on the ground of liquidation or transformation of public facilities. Establishing of hospitals wholly on the basis of private initiative and resources is called "founding privatisation" (7).

${ }^{6}$ The remaining part are the cost of the pharmaceutics (excluding those utilised by the facilities), rehabilitation tools, administrative costs and public health expenses (20).
} 
jeńskie (Kujawsko-Pomorskie Voivodeship), in the beginning of 2002 the hospital was taken over by the commercial company, in which one third of stocks was held by the self-government, one third - by the workers of the hospital, and remaining one third - by a bank. At the beginning this hospital was an example of very successful privatisation. The covenants were covered by poviat self-government, which issued 8-year bonds for the amount of PLN 2 millions 7 . This operation enabled the new body to act without any financial liabilities. The hospital provided activity economically very efficacious, despite of the limited resources from contracts with public health insurance fund. Nevertheless, finally it became first in Poland private hospital that was constrained to declare the bankruptcy. The direct reason of the bankruptcy was the court's decision obliging the private company to pay workers the covenants deriving from the so-called "203 Law". This sentence caused major legal doubts, for it referred to the period after establishing private hospital, while the "203 Law" referred to public facilities only. Covenants of this title referring to the period before the liquidation of the public hospital were paid by the local self-government (it amounted to about PLN $630000^{9}$ ). Both the "203 Law" (evident case of political populism) and doubtful court's sentence shows the significance of legal obstacles blocking the process of privatisation ${ }^{10}$.

\section{CONCLUSIONS}

1. Despite of the systematically increasing number of private inpatient care facilities in Poland, the role of private hospitals in health care system is still significantly limited. The results of opening out-patient care sector for the private initiative should be an evidence that privatisation has a positive impact on the organisational and economical efficiency of the health care system.

2. The incoherence and insufficient quality of the legal regulations concerning the privatisation of the in-patient care sector causes a need of complex legislative actions that shall be taken for regulation of this area.

3. Privatisation of hospitals should not be pursued without connection with the wider structural changes of the health care system, including the institution of payer. The centralised monopsonic health insurance fund may be an obstacle for the process of privatisation. The politically dependent health insurance institution, particularly under the pressure of mercantilist professional groups, may be dangerous for the already existing private health care facilities.

\section{REFERENCES}

1. Csonka A. Hungary makes slow progress in health-system reform. Lancet. 2004 Jun 12;363(9425):1957-60.

2. Network of health establishments. Prague: Institute of Health Information and Statistics of the Czech Republic; 2004. (In Czech.)

3. Bed care. Prague: Institute of Health Information and Statistics of the Czech Republic; 2004. (In Czech.)

4. Health Care Systems in Transition. Czech Republic. Copenhagen: European Observatory on Health Care Systems; 2000.

5. Watson N. Central Europe dabbles in private health. Lancet. 2004 Nov 13-19;364(9447):1745-6.

6. Kłos K. Assumptions of the privatisation of regional independent public health care facilities in Malopolska. Krakow: Office of the Malopolskie Voivodeship Marshall; 2000. (In Polish.)

7. Jaworska-Łuczak B. Privatisation in health care in Poland - analysis of the present state and future prognosis. Zdrow Publiczne. 2002;112(1):93-101. (In Polish.)

8. Kleszcz H. Market approach. Szpital Polski. 2004;4:II-III. (In Polish.)

9. Ostrowski T, Wdowiak L. Privatisation of health care in Poland. Zdrow Publiczne. 2002;112(1):86-92. (In Polish.)

10. Walaszkiewicz B. I will buy a hospital in province. Newsweek Polska. 2004;39:24. (In Polish.)

11. Włodarczyk C. Health reforms. Universal problem. Krakow: Jagiellonian University Publishing Office; 2003. (In Polish.)

12. Golinowska $S$. The health care system after three years of reforming - a synthetic report. In: Golinowska S, editor. Health care in Poland after the reform. Warsaw: Centre for Socio-Economic Analyses; 2002. p. 11-42. (In Polish.)

13. Rondinelli D, Nellis J, Shabbir Cheema G. Decentralization in developing countries: a review of recent experience. Washington D.C.: World Bank; 1983.

14. Bossert T. Analyzing the decentralization of health care systems in developing countries: decision space, innovation and performance. Soc Sci Med. 1998;47(10):1513-27.

15. Krajewski-Siuda K, Romaniuk P. Why the National Health Fund could be implemented? Zdrowie i Zarządzanie. 2004;1(VI):36-42. (In Polish.)

16. Dercz $M$, Izdebski H. How to privatise independent public health care facilities due to current law regulations. Warsaw: Ministry of Health. (In Polish.)

17. Woźniak Z, Drozdowski R, Godlewska K. Analysis and the assessment of the chances to implement the project of the Law on Commercialisation and Privatisation of the Public Health Care. Unpublished analysis performed within the Political Cabinet of the Minister of Health in 2001. (Owned by authors.) (In Polish.)

18. Bonifrater Order Hospital in Krakow Website [cited 2005 June 9]. Available from: http://www.bonifratrzy.krakow.pl/indexf770.html.

19. Statistical Bulletin of the Ministry of Health. Warsaw: The Centre of the Computer Systems in Health Care; 2005. (In Polish.)

20. Walewski P. In colour bedding. Polityka. 2005; 17. (In Polish.)

21. Polish Private Hospitals Association Website [cited 2005 June 9]. Available from: http://www.szpitale.org/czlonkowie.php.

22. The report on financing health care in Poland - The Green Book. Warsaw: Ministry of Health; 2004. (In Polish.)

23. The statement of the Polish Private Hospitals Association of 24.10.2003 [cited 2005 June 9]. Available from: http://www.szpitale.org/info7.php.

Received August 29, 2005 Received in revised form and accepted November 4, 2005

\footnotetext{
7 Average EUR 500,000.

${ }^{8}$ Very controversial act passed by the parliament in 2001 on the demand of nurses, obliging the public health care facilities to raise all workers' salaries of gross PLN 203 (EUR 52).

9 Average EUR 158,000.

${ }^{10}$ Currently the hospital in Więcbork is owned by new company in which $100 \%$ of stocks is held by poviat. All data concerning the privatisation of hospital in Więcbork were collected during telephone interview with Stanisław Drozdowski, starosta (prefect) of the Sępólno Krajeńskie Poviat.
} 